Journal of Mathematics and Statistics 5 (1): 65-71, 2009

ISSN 1549-3644

(C) 2009 Science Publications

\title{
Fuzzy Reliability and Fuzzy Availability of the Serial Process in Butter-Oil Processing Plant
}

\author{
${ }^{1}$ Kuldeep Kumar, ${ }^{2}$ Jai Singh and ${ }^{1}$ Pawan Kumar \\ ${ }^{1}$ Department of Mathematics, \\ National Institute of Technology, Kurukshetra, Haryana, India \\ ${ }^{2}$ Modern Institute of Engineering and Technology, Mohri, Kurukshetra, India
}

\begin{abstract}
Problem statement: The purpose of this study was to compute fuzzy reliability and fuzzy availability of the serial process in butter-oil processing plant for various choices of failure and repair rates of sub-system. This plant consists of eight sub-systems out of which two are supported by standby units with perfect switch over devices and considered that these two sub-systems never fail. The effect of coverage factor on the fuzzy availability also studied. Approach: In this study the chapmanKolmogorov differential equations were formed using mnemonic rule from the transition diagram of the butter-oil processing plant. These equations were solved for steady state recursively and results were obtained by computer program. Results: Result in the study analyzed fuzzy availability for various values of system coverage factor, failure and repair rates. Industrial implications of the results also briefly discussed. Conclusion: The findings in the study suggested that the management of butteroil processing plant's sensitive sub-system is important to improve its performance.
\end{abstract}

Key words: Manufacturing system, modeling, markov processes, fuzzy reliability

\section{INTRODUCTION}

Conventional reliability theory considers the assumptions of the probability theory and the binary states of a component/system as working or failed. Of late, there has been tremendous growth in the area of fuzzy set theory ${ }^{[7]}$. This has changed the basic scenario in reliability and concerned theories. Though conventional reliability theory cannot be ignored, fuzzy reliability theory also needs to be considered along with it. In this study, fuzzy reliability refers to profust reliability. Profust reliability approach ${ }^{[1,8,9,10,11]}$ is based on the probabilistic assumption and the fuzzy state assumption. The failure behavior of the system is fully assumed to follow probability measures. The system's operating and failed states are described by fuzzy states. The system can be in any fuzzy state at any given point of time. The system's failure or success is viewed in a fuzzy way. Many researchers applied this concept on various systems. Chowdhury and Misra ${ }^{[3]}$ presented a method to find an expression of fuzzy system reliability of a non-series parallel network taking into consideration the special requirements of fuzzy sets. Zuang $^{[4]}$ presented a method of reliability analysis in the presence of fuzziness attached to operating time. $\mathrm{Cai}^{\left[{ }^{[5]}\right.}$ described a method of fuzzy reliability for street- lighting lamps replacement. Cai et al. ${ }^{[2]}$ applied this concept for evaluating fuzzy reliability modeling of gracefully degradable computing systems.

Pandey et al. ${ }^{[6]}$ also found the profust reliability of a gracefully degradable system. In this study, we propose to solve the governing differential equations of the system to find the profust reliability and fuzzy availability of the serial processes in butter-oil processing plant using both failure and repair rates. If any subsystem fails, then the system will immediately take reconfiguration operation within no time. The reconfiguration operation will detect and remove the failed subsystem from the system, however; all the other operating subsystem will continue to operate as it is. The probability of successful reconfiguration operation is defined as coverage factor. We denote this reconfiguration parameter or system coverage factor by c. The major motivation of this study is to bring fuzzy reliability theory into a real-world applicable maintenance problem.

\section{MATERIALS AND METHODS}

The reliability can be interpreted as the probability that no transition occurs from the system success state to the system failure state. Evidently, in the presence of

Corresponding Author: Pawan Kumar, Department of Mathematics, National Institute of Technology, Kurukshetra, Haryana, India Tel: +919416373190 
fuzziness attached to the system states, both the definition of system failure and that of reliability should be modified. In response to this requirement, we introduce the concept of fuzzy reliability:

Suppose a system with $\mathrm{n}$ topological (non-fuzzy) states $\mathrm{S}_{1}, \mathrm{~S}_{2}, \ldots, \mathrm{S}_{\mathrm{n}}$.

Let $U=\left\{S_{1}, S_{2}, \ldots, S_{n}\right\}$ denote the universe of discourse. On this universe we define a fuzzy success state:

$\tilde{\mathrm{S}}=\left\{\left(\mathrm{S}_{\mathrm{i}}, \mu_{\tilde{\mathrm{s}}}\left(\mathrm{S}_{\mathrm{i}}\right)\right), \mathrm{i}=1,2, \ldots \mathrm{n}\right\}$

and a fuzzy failure state:

$\tilde{\mathrm{F}}=\left\{\left(\mathrm{S}_{\mathrm{i}}, \mu_{\tilde{\mathrm{F}}}\left(\mathrm{S}_{\mathrm{i}}\right)\right), \mathrm{i}=1,2, \ldots \mathrm{n}\right\}$

where, $\mu_{\mathrm{s}}\left(\mathrm{S}_{\mathrm{i}}\right)$ and $\mu_{\mathrm{F}}\left(\mathrm{S}_{\mathrm{i}}\right)$ are the corresponding membership functions, respectively. In the conventional reliability theory, one is interested in the event of transition from the system success state to system failure state. Accordingly, here we are interested in the event, denoted by $\mathrm{T}_{\mathrm{SF}}$ of the transition from the fuzzy success state to fuzzy failure state. Assume that the universe $\mathrm{U}$ or the behavior of $\mathrm{n}$ system states is completely stochastically characterized in the time domain, we define:

$$
\mathrm{R}\left(\mathrm{t}_{0}, \mathrm{t}_{0}+\mathrm{t}\right)=\operatorname{Pr}\left\{\begin{array}{l}
\mathrm{T}_{\mathrm{SF}} \text { does not occur in } \\
\text { the timeinterval }\left[\mathrm{t}_{0}, \mathrm{t}_{0}+\mathrm{t}\right]
\end{array}\right\}
$$

$\mathrm{R}\left(\mathrm{t}_{0}, \mathrm{t}_{0}+\mathrm{t}\right)$ is referred to as the fuzzy interval reliability of the system in $\left[\mathrm{t}_{0}, \mathrm{t}_{0}+\mathrm{t}\right]$. To compute the fuzzy interval reliability, we must express $\mathrm{T}_{\mathrm{SF}}$. Since both $\mathrm{S}$ and $\mathrm{F}$ are fuzzy states, the transitions between them are consequently fuzzy and thus $\mathrm{T}_{\mathrm{SF}}$ can be viewed as a fuzzy event ${ }^{[6]}$. Apparently $\mathrm{T}_{\mathrm{SF}}$ may occur only when some state transition occurs among the $n$ system states $\left\{S_{1}, S_{2}, \ldots, S_{n}\right\}$, so $T_{S F}$ can be defined on the universe:

$\mathrm{U}_{\mathrm{T}}=\left\{\mathrm{m}_{\mathrm{ij}}, \mathrm{i}, \mathrm{j}=1,2, \ldots, \mathrm{n}\right\}$

where, $m_{i j}$ represents the transition from state $S_{i}$ to $S_{j}$ with membership function:

$$
\begin{aligned}
& \left\{\mu_{T_{S F}}\left(m_{i j}\right), i, j=1,2, \ldots, n\right\} \\
& \text { i.e., } T_{S F}=\left\{m_{i j}, \mu_{T_{S F}}\left(m_{i j}\right), i, j=1,2, \ldots, n\right\}
\end{aligned}
$$

Let:

$\gamma_{\mathrm{F} / \mathrm{S}}\left(\mathrm{S}_{\mathrm{i}}\right)=\frac{\mu_{\mathrm{F}}\left(\mathrm{S}_{\mathrm{i}}\right)}{\mu_{\mathrm{F}}\left(\mathrm{S}_{\mathrm{i}}\right)+\mu_{\mathrm{S}}\left(\mathrm{S}_{\mathrm{i}}\right)}$

Then $\gamma_{\mathrm{F} / \mathrm{S}}\left(\mathrm{S}_{\mathrm{i}}\right)$ can be interpreted as the grade of membership of $S_{i}$, with respect to $S$ to $F$. it is reasonable to say that the transition from $S_{i}$ to $S_{j}$ makes the transition from $S$ to $F$ occur to some extent if and only if the relation $\gamma_{\mathrm{F} / \mathrm{S}}\left(\mathrm{S}_{\mathrm{j}}\right)>\gamma_{\mathrm{F} / \mathrm{S}}\left(\mathrm{S}_{\mathrm{i}}\right)$ holds. We therefore define:

$\mu_{\mathrm{T}_{\mathrm{SF}}}\left(\mathrm{m}_{\mathrm{ij}}\right)=\left\{\begin{array}{cc}\gamma_{\mathrm{F} / \mathrm{S}}\left(\mathrm{S}_{\mathrm{j}}\right)-\gamma_{\mathrm{F} / \mathrm{S}}\left(\mathrm{S}_{\mathrm{i}}\right) & \text { when } \gamma_{\mathrm{F} / \mathrm{S}}\left(\mathrm{S}_{\mathrm{j}}\right)>\gamma_{\mathrm{F} / \mathrm{S}}\left(\mathrm{S}_{\mathrm{i}}\right) \\ 0 & \text { otherwise }\end{array}\right.$

Then the fuzzy interval reliability can be expressed as:

$$
\begin{aligned}
\mathrm{R}\left(\mathrm{t}_{0}, \mathrm{t}_{0}+\mathrm{t}\right)= & 1-\sum_{\mathrm{i}=1}^{\mathrm{n}} \sum_{\mathrm{j}=1}^{\mathrm{n}} \mu_{\mathrm{T}_{\mathrm{SF}}}\left(\mathrm{m}_{\mathrm{ij}}\right) \operatorname{Pr} \\
& \left\{\mathrm{m}_{\mathrm{ij}} \text { occurs during }\left[\mathrm{t}_{0}, \mathrm{t}_{0}+\mathrm{t}\right]\right\}
\end{aligned}
$$

where, $\mathrm{m}_{\mathrm{ij}}$ is confined to be the transition from $\mathrm{S}_{\mathrm{i}}$ to $\mathrm{S}_{\mathrm{j}}$ without passing via any intermediate state.

Let $\mathrm{t}_{0}=0$; we have:

$\mathrm{R}\left(\mathrm{t}_{0}, \mathrm{t}_{0}+\mathrm{t}\right)=\mathrm{R}(\mathrm{t})$

$R(t)$ is referred to as the fuzzy reliability of the system at time t. Here it is necessary to point out that the applicability of (4-6) is not confined to the area of reliability research. [They can be used to define any transition between two fuzzy states, provided that we recall that a transition between two fuzzy states is just a fuzzy event.]. Equation 4-6 are a foundation for characterizing the behavior of fuzzy stochastic process with fuzzy states. [For the reliability purpose, we generally, but not necessarily, define: $\mu_{\overline{\mathrm{F}}}\left(\mathrm{S}_{\mathrm{i}}\right)=1-\mu_{\tilde{\mathrm{S}}}\left(\mathrm{S}_{\mathrm{i}}\right)$ $\mathrm{i}=1,2 \ldots, \mathrm{n}]$.

Suppose that without passing via any intermediate state, $S_{j}$ can not go to other states except $S_{j-1}$ and $\mu_{\tilde{F}}\left(S_{j}\right)<\mu_{\tilde{F}}\left(S_{j-1}\right)$ for $j=1,2 \ldots n$.

Then we have:

$$
R\left(t_{0}, t_{0}+t\right)=1-\sum_{j=1}^{n-1} \mu_{T_{S F}}\left(m_{(j+1) j}\right) \operatorname{Pr}\left\{\begin{array}{l}
m_{(j+1) j} \text { occurs } \\
\text { during }\left[t_{0}, t_{0}+t\right]
\end{array}\right\}
$$

Suppose at time $t_{0}$ the system is in $S_{n}$. Then at time $t_{0}+t$ the system is in $S_{j}$ implies that $m_{n(n-1)} \ldots m_{(j+1) j}$ have occurred during $\left[\mathrm{t}_{0}, \mathrm{t}_{0}+\mathrm{t}\right]$. So: 
$\operatorname{Pr}\left\{\begin{array}{l}\mathrm{m}_{(\mathrm{j}+1) \mathrm{j}} \text { occurs } \\ \text { during }\left[\mathrm{t}_{0}, \mathrm{t}_{0}+\mathrm{t}\right]\end{array}\right\}=\sum_{\mathrm{i}=1}^{\mathrm{j}} \operatorname{Pr}\left\{\begin{array}{l}\text { at time } \mathrm{t}_{0}+\mathrm{t} \text { the } \\ \text { system is in } \mathrm{S}_{\mathrm{i}}\end{array}\right\}$

Also we note that:

$$
\mu_{\mathrm{T}_{\mathrm{SF}}}\left(\mathrm{m}_{\mathrm{ij}}\right)=\mu_{\mathrm{T}_{\mathrm{SF}}}\left(\mathrm{m}_{\mathrm{ik}}\right)+\mu_{\mathrm{T}_{\mathrm{SF}}}\left(\mathrm{m}_{\mathrm{kj}}\right)
$$

if $\mu_{\tilde{F}}\left(S_{i}\right)<\mu_{\tilde{F}}\left(S_{k}\right)<\mu_{\tilde{F}}\left(S_{j}\right)$.

Then we have:

$$
\begin{aligned}
\mathrm{R}\left(\mathrm{t}_{0}, \mathrm{t}_{0}+\mathrm{t}\right) & =1-\sum_{\mathrm{j}=1}^{\mathrm{n}-1} \mu_{\mathrm{T}_{\mathrm{SF}}}\left(\mathrm{m}_{\mathrm{nj}}\right) \cdot \operatorname{Pr}\left\{\begin{array}{l}
\text { at time } \mathrm{t}_{0}+\mathrm{t} \text { the } \\
\text { system is in } \mathrm{S}_{\mathrm{i}}
\end{array}\right\} . \\
& =\sum_{\mathrm{j}=1}^{\mathrm{n}-1} \mu_{T_{\mathrm{SF}}}^{\mathrm{C}}\left(\mathrm{m}_{\mathrm{nj}}\right) \cdot \operatorname{Pr}\left\{\begin{array}{l}
\text { at time } \mathrm{t}_{0}+\mathrm{t} \\
\text { the system is in } \mathrm{S}_{\mathrm{i}}
\end{array}\right\}
\end{aligned}
$$

Where:

$$
\mu_{\mathrm{T}_{\mathrm{SF}}}^{\mathrm{C}}\left(\mathrm{m}_{\mathrm{ij}}\right)=1-\mu_{\mathrm{T}_{\mathrm{SF}}}\left(\mathrm{m}_{\mathrm{ij}}\right) \mathrm{i}, \mathrm{j}=1,2 \ldots \mathrm{n}
$$

The system, notations and assumptions: In this study, we discuss Butter-oil manufacturing plant which consists of eight sub-systems out of which two pump and chiller are supported by stand-by units with perfect switch over devices and considered that these two systems never fail. The mathematical modeling is carried out for the remaining six sub-systems that are prone to failure:

Sub-system A (Separator): Chilled milk from the chiller is taken to the cream separator, where fats are separated from the milk in the form of cream containing $40-50 \%$ and the remaining skimmed milk is stored in milk silos for preparing milk powder. It consists of three components in series, namely, motor, bearings and high-speed gearbox.

Sub-system B (Pasteurizer): Cream from the separator is pasteurized in this sub-system. Pasteurization is the process of heating every particle of cream to not less than $70^{\circ} \mathrm{C}$. Its purpose is to destroy pathogenic organisms, to inactivate the enzymes present and to make possible removal of volatile flavors. There are two pasteurizers working in parallel. If one fails the system works in reduced capacity. The pasteurized cream is stored in double-jacketed cream storage tank for further processing.

Sub-system C (Continuous butter making): Cream from the cream storage tank is pumped into the Continuous Butter Making machine (CBM). The cream is churned in this machine in order to get butter granules. The buttermilk produced in this process is pumped back to raw milk silos and the butter granules are further processed in the machine so as to get homogeneous mass of butter. The homogeneous butter is taken out from machine into butter trolleys and shifted to melting vats. The CBM consists of gearbox, motor and bearings in series.

Sub-system D (Melting vats): This sub-system consists of a double-jacketed storage tank. Butter is melted in this research at about $107^{\circ} \mathrm{C}$ very gently so that the water evaporates from the melting butter. The melting butter is then allowed to remain undisturbed for about half an hour. This sub-system consists of monoblock pumps, motors and bearing in series.

Sub-system E (Butter-oil clarifier): Butter-oil from melting vats is taken out into butter oil settling tanks where it is allowed to settle for a few hours. After this the fine particles of butter-oil residue are removed from the butter-oil and then butter oil is stored in storage tanks. Now, it is cooled to a temperature of $28-30^{\circ} \mathrm{C}$ suitable for storage of butter-oil. This sub-system consists of motors and gearbox in series.

Sub-system F (Packaging): In this sub-system the packets of processed butter-oil are created using a pouch-filling machine. It is fill, flow and seal automatic machine. This sub-system consists of printed circuit board and pneumatic cylinder in series.

Mathematical formulation of the system: To determine fuzzy reliability and long run fuzzy availability of a butter-oil manufacturing plant, the mathematical formation of the model is carried out using mnemonic rule for six sub-systems.

Transient state: In order to find fuzzy reliability of this system, we have formed a system of linear differential equations using mnemonic rule from the transition diagram. According to this rule, the derivative of the probability of every state is equal to the sum of all probability flows which comes from other states to the given state minus the sum of all probability flows which goes out from the given state to the other states. The differential equations formed in this way are known as the Chapman Kolmogorov differential equations. Now the first order differential equations associated with the transition diagram (Fig. 1):

$$
\begin{aligned}
\frac{d P_{1}(t)}{d t}+Y_{1} P_{1}(t)= & \beta_{2} P_{2}(t)+\beta_{1} P_{3}(t)+\beta_{3} P_{4}(t) \\
& +\beta_{4} P_{5}(t)+\beta_{5} P_{6}(t)+\beta_{6} P_{7}(t)
\end{aligned}
$$




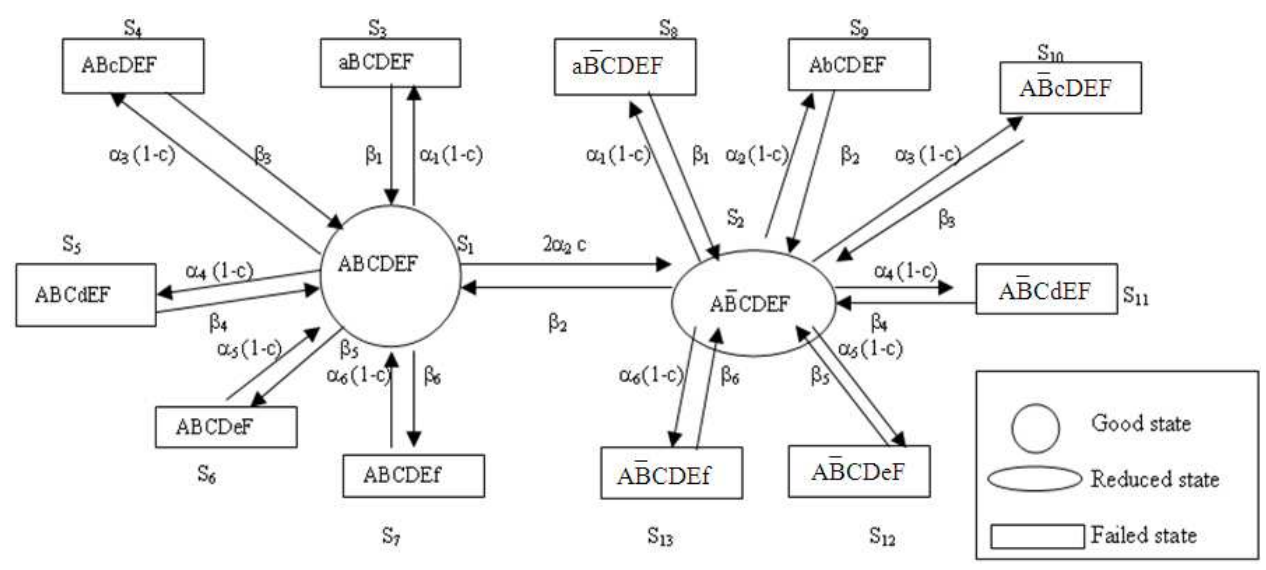

Fig. 1: Transition diagram

$$
\begin{aligned}
& \frac{d P_{2}(t)}{d t}+Y_{2} P_{2}(t)=2 \alpha_{2} c P_{1}(t)+\beta_{1} P_{8}(t)+\beta_{2} P_{9}(t) \\
& +\beta_{3} P_{10}(t)+\beta_{4} P_{11}(t)+\beta_{5} P_{12}(t)+\beta_{6} P_{13}(t) \\
& \frac{d P_{3}(t)}{d t}+\beta_{1} P_{3}(t)=\alpha_{1}(1-c) P_{1}(t) \\
& \frac{d P_{i+1}(t)}{d t}+\beta_{i} P_{i+1}(t)=\alpha_{i}(1-c) P_{1}(t), i=3,4,5,6 \\
& \frac{d P_{7+i}(t)}{d t}+\beta_{i} P_{7+i}(t)=\alpha_{i}(1-c) P_{2}(t), i=1,2,3,4,5,6
\end{aligned}
$$

Where:

$$
Y_{1}=\left[\begin{array}{l}
2 \alpha_{2} c+\alpha_{1}(1-c)+\alpha_{3}(1-c)+ \\
\alpha_{4}(1-c)+\alpha_{5}(1-c)+\alpha_{6}(1-c)
\end{array}\right]
$$

$Y_{2}=\left[\beta_{2}+\alpha_{1}(1-c)+\alpha_{2}(1-c)+\alpha_{3}(1-c)+\alpha_{4}(1-c)+\alpha_{5}(1-\right.$ c) $\left.+\alpha_{6}(1-c)\right]$

\section{With initial conditions:}

$\mathrm{P}_{\mathrm{k}}(0)=1$, if $\mathrm{k}=1$

0 , Otherwise

The fuzzy reliability $R_{P F}(t)$ of the system can be computed by:

$$
\mathrm{R}_{\mathrm{PF}}(\mathrm{t})=\mathrm{P}_{1}(\mathrm{t})+\frac{1}{2} \mathrm{P}_{2}(\mathrm{t})
$$

Steady state: In process industries, management is generally interested in the long run fuzzy availability of the system. So the steady state probabilities of the system are also needed. Steady state probabilities of the system are obtained from the condition when $\mathrm{t} \rightarrow \infty, \frac{\mathrm{d}}{\mathrm{dt}} \rightarrow 0$. In this state, Eq. 11-15 reduce to the following system of equations. Here, we have used $P_{i}$ for $\mathrm{P}_{\mathrm{i}}(\mathrm{t} \rightarrow \infty) \mathrm{i}=1,2 \ldots \ldots .13$ :

$\mathrm{Y}_{1} \mathrm{P}_{1}=\beta_{2} \mathrm{P}_{2}+\beta_{1} \mathrm{P}_{3}+\beta_{3} \mathrm{P}_{4}+\beta_{4} \mathrm{P}_{5}+\beta_{5} \mathrm{P}_{6}+\beta_{6} \mathrm{P}_{7}$

$\mathrm{Y}_{2} \mathrm{P}_{2}=2 \alpha_{2} c \mathrm{P}_{1}+\beta_{1} \mathrm{P}_{8}+\beta_{2} \mathrm{P}_{9}+\beta_{3} \mathrm{P}_{10}+\beta_{4} \mathrm{P}_{11}+\beta_{5} \mathrm{P}_{12}+\beta_{5} \mathrm{P}_{13}$

$\beta_{1} \mathrm{P}_{3}=\alpha_{5}(1-\mathrm{c}) \mathrm{P}_{1}$

$\beta_{\mathrm{i}} \mathrm{P}_{\mathrm{i}+1}=\alpha_{\mathrm{i}}(1-\mathrm{c}) \mathrm{P}_{1}, \mathrm{i}=3,4,5,6$

$\beta_{\mathrm{i}} \mathrm{P}_{7+\mathrm{i}}=\alpha_{\mathrm{i}}(1-\mathrm{c}) \mathrm{P}_{2}, \mathrm{i}=1,2,3,4,5,6$

Let:

$$
\delta_{i}=\frac{\alpha_{i}(1-c)}{\beta_{i}} i=1,2 \ldots 6
$$

Solving these equations recursively, we get:

$\mathrm{P}_{2}=2 \mathrm{kc} \mathrm{P}_{1}$ where, $\mathrm{k}=\frac{\alpha_{2}}{\beta_{2}}$

$\mathrm{P}_{3}=\delta_{1} \mathrm{P}_{1}$

$\mathrm{P}_{\mathrm{i}+1}=\delta_{1} \mathrm{P}_{1}, \mathrm{i}=3,4,5,6$.

$\mathrm{P}_{7+\mathrm{i}}=2 \mathrm{kc} \delta_{1} \mathrm{P}_{1}, \mathrm{i}=1,2,3,4,5,6$

Now, using the normalizing condition:

$$
\sum_{i=1}^{13} P_{i}=1
$$

We get:

$$
\mathrm{P}_{1}=\left[(1+2 \mathrm{kc})\left(1+\delta_{1}+\delta_{3}+\delta_{4}+\delta_{5}+\delta_{6}\right)+2 \mathrm{kc}_{2}\right]^{-1}
$$

Now we know long run fuzzy availability $\mathrm{A}(\infty)$ can be calculated using: 


$$
\mathrm{A}(\infty)=\mathrm{P}_{1}+\frac{1}{2} \mathrm{P}_{2}
$$

\section{RESULTS}

Numerical analysis: The effect of various parameters on fuzzy availability is studied for steady state. If the failure, repair rates and coverage factors are altered, the fuzzy availability is affected. This effect is shown in Table 1-3.

Table 1: Fuzzy availability corresponding to failure rates of separator and CBM

\begin{tabular}{|c|c|c|c|c|}
\hline$\downarrow \alpha_{3}$ & & $\alpha_{1} \rightarrow$ & & \\
\hline$c=0.0$ & 0.006 & 0.007 & 0.008 & 0.009 \\
\hline 0.0050 & 0.971090 & 0.968795 & 0.966512 & 0.964239 \\
\hline 0.0052 & 0.970809 & 0.968515 & 0.966233 & 0.963961 \\
\hline 0.0054 & 0.970557 & 0.968235 & 0.965954 & 0.963684 \\
\hline $\begin{array}{l}0.0056 \\
\mathbf{c}=\mathbf{0 . 1}\end{array}$ & 0.970246 & 0.967956 & 0.965676 & 0.963407 \\
\hline 0.0050 & 0.973241 & 0.971165 & 0.966512 & 0.967039 \\
\hline 0.0052 & 0.972986 & 0.970912 & 0.968845 & 0.966766 \\
\hline 0.0054 & 0.971971 & 0.970623 & 0.968593 & 0.966537 \\
\hline $\begin{array}{l}0.0056 \\
\mathbf{c}=\mathbf{0 . 2}\end{array}$ & 0.971689 & 0.970405 & 0.968341 & 0.966286 \\
\hline 0.0050 & 0.971815 & 0.964926 & 0.968138 & 0.966311 \\
\hline 0.0052 & 0.970080 & 0.973327 & 0.971479 & 0.969639 \\
\hline 0.0054 & 0.969855 & 0.973100 & 0.971254 & 0.969414 \\
\hline $\begin{array}{l}0.0056 \\
\mathbf{c}=\mathbf{0 . 3}\end{array}$ & 0.969630 & 0.972874 & 0.971042 & 0.969189 \\
\hline 0.0050 & 0.977592 & 0.975971 & 0.974333 & 0.972712 \\
\hline 0.0052 & 0.977392 & 0.975740 & 0.974134 & 0.972514 \\
\hline 0.0054 & 0.977190 & 0.975561 & 0.973936 & 0.972316 \\
\hline $\begin{array}{l}0.0056 \\
\mathbf{c}=\mathbf{0 . 4}\end{array}$ & 0.976992 & 0.975362 & 0.973737 & 0.972118 \\
\hline 0.0050 & 0.979792 & 0.978385 & 0.976983 & 0.975584 \\
\hline 0.0052 & 0.979619 & 0.978213 & 0.976811 & 0.975413 \\
\hline 0.0054 & 0.979447 & 0.978042 & 0.976640 & 0.975242 \\
\hline $\begin{array}{l}0.0056 \\
\mathbf{c}=\mathbf{0 . 5}\end{array}$ & 0.979275 & 0.977870 & 0.976469 & 0.975071 \\
\hline 0.0050 & 0.982008 & 0.980774 & 0.979654 & 0.978480 \\
\hline 0.0052 & 0.981861 & 0.980685 & 0.979510 & 0.978337 \\
\hline 0.0054 & 0.981719 & 0.980541 & 0.979342 & 0.978194 \\
\hline $\begin{array}{l}0.0056 \\
\mathbf{c}=\mathbf{0 . 6}\end{array}$ & 0.981575 & 0.980397 & 0.979223 & 0.978051 \\
\hline 0.0050 & 0.984241 & 0.983293 & 0.982346 & 0.981402 \\
\hline 0.0052 & 0.984124 & 0.983177 & 0.982231 & 0.981287 \\
\hline 0.0054 & 0.984008 & 0.983061 & 0.982115 & 0.981171 \\
\hline $\begin{array}{l}0.0056 \\
\mathbf{c}=\mathbf{0 . 7}\end{array}$ & 0.983892 & 0.982945 & 0.981999 & 0.981056 \\
\hline 0.0050 & 0.986490 & 0.985775 & 0.985061 & 0.984348 \\
\hline 0.0052 & 0.986402 & 0.985775 & 0.984974 & 0.984261 \\
\hline 0.0054 & 0.986315 & 0.985600 & 0.984887 & 0.984174 \\
\hline $\begin{array}{l}0.0056 \\
\mathbf{c}=\mathbf{0 . 8}\end{array}$ & 0.986227 & 0.095513 & 0.984799 & 0.984087 \\
\hline 0.0050 & 0.988756 & 0.988277 & 0.987798 & 0.987320 \\
\hline 0.0052 & 0.988698 & 0.988218 & 0.987740 & 0.987261 \\
\hline 0.0054 & 0.988639 & 0.988160 & 0.987681 & 0.987203 \\
\hline $\begin{array}{l}0.0056 \\
\mathbf{c}=\mathbf{0 . 9}\end{array}$ & 0.988580 & 0.988101 & 0.987623 & 0.987144 \\
\hline 0.0050 & 0.991040 & 0.990799 & 0.990558 & 0.990317 \\
\hline 0.0052 & 0.991010 & 0.990769 & 0.990528 & 0.990288 \\
\hline 0.0054 & 0.990981 & 0.990740 & 0.990499 & 0.990258 \\
\hline 0.0056 & 0.990951 & 0.990710 & 0.990469 & 0.990229 \\
\hline
\end{tabular}

Effect of failure rates of separator and Continuous Butter Making (CBM) on long run fuzzy availability: The effect on the system is studied by varying the values of $\alpha_{1}$ and $\alpha_{3}$. Let the values be $\alpha_{2}=0.0027, \alpha_{4}=0.0009, \alpha_{5}=0.0027, \alpha_{6}=0.0055$, $\beta_{1}=0.41, \quad \beta_{2}=0.40, \quad \beta_{3}=0.67, \beta_{4}=0.33, \beta_{5}=0.67$, $\beta_{6}=6.00$.

Table 2: Fuzzy availability corresponding to failure rates of separator and melting vats

\begin{tabular}{|c|c|c|c|c|}
\hline \multirow[t]{2}{*}{$\downarrow \alpha_{4}$} & \multicolumn{3}{|c|}{$\alpha_{1} \rightarrow$} & \multirow[b]{2}{*}{0.009} \\
\hline & 0.006 & 0.007 & 0.008 & \\
\hline $\begin{array}{l}\mathbf{c}=\mathbf{0 . 0} \\
0.0010\end{array}$ & 0.969821 & 0.967532 & 0.965254 & 0.962987 \\
\hline 0.0012 & 0.969251 & 0.966965 & 0.964690 & 0.962425 \\
\hline 0.0014 & 0.968682 & 0.966399 & 0.964126 & 0.961864 \\
\hline \multicolumn{5}{|l|}{$c=0.1$} \\
\hline 0.0010 & 0.972018 & 0.969947 & 0.967885 & 0.965831 \\
\hline 0.0012 & 0.971503 & 0.969434 & 0.967374 & 0.965322 \\
\hline 0.0014 & 0.970988 & 0.968921 & 0.966863 & 0.964814 \\
\hline \multicolumn{5}{|l|}{$c=0.2$} \\
\hline 0.0010 & 0.974234 & 0.972382 & 0.970538 & 0.968701 \\
\hline 0.0012 & 0.973773 & 0.971924 & 0.970081 & 0.968246 \\
\hline 0.0014 & 0.973313 & 0.971465 & 0.969624 & 0.967791 \\
\hline 0.0016 & 0.972853 & 0.971007 & 0.969168 & 0.967336 \\
\hline \multicolumn{5}{|l|}{$c=0.3$} \\
\hline 0.0010 & 0.976467 & 0.974838 & 0.973215 & 0.971597 \\
\hline 0.0012 & 0.976062 & 0.974434 & 0.972812 & 0.971195 \\
\hline 0.0014 & 0.975657 & 0.974031 & 0.972410 & 0.970794 \\
\hline \multicolumn{5}{|l|}{$c=0.4$} \\
\hline 0.0010 & 0.978718 & 0.977314 & 0.975914 & 0.974518 \\
\hline 0.0012 & 0.978369 & 0.976966 & 0.975567 & 0.974172 \\
\hline 0.0014 & 0.978020 & 0.976618 & 0.975220 & 0.973826 \\
\hline \multicolumn{5}{|l|}{$c=0.5$} \\
\hline 0.0010 & 0.980987 & 0.979811 & 0.978637 & 0.977466 \\
\hline 0.0012 & 0.980695 & 0.979519 & 0.978346 & 0.977175 \\
\hline 0.0014 & 0.980402 & 0.979227 & 0.978055 & 0.976885 \\
\hline 0.0016 & 0.980110 & 0.978935 & 0.977764 & 0.976595 \\
\hline \multicolumn{5}{|l|}{$c=0.6$} \\
\hline 0.0010 & 0.983275 & 0.982328 & 0.981383 & 0.980440 \\
\hline 0.0012 & 0.983039 & 0.982093 & 0.981149 & 0.980206 \\
\hline 0.0014 & 0.982804 & 0.981858 & 0.980915 & 0.979972 \\
\hline 0.0016 & 0.982569 & 0.981624 & 0.980680 & 0.979739 \\
\hline \multicolumn{5}{|l|}{$c=0.7$} \\
\hline 0.0010 & 0.985581 & 0.984867 & 0.984154 & 0.983442 \\
\hline 0.0012 & 0.985403 & 0.984689 & 0.983977 & 0.983265 \\
\hline 0.0014 & 0.985226 & 0.984512 & 0.983800 & 0.983088 \\
\hline \multicolumn{5}{|l|}{$c=0.8$} \\
\hline 0.0010 & 0.987905 & 0.987426 & 0.986948 & 0.986471 \\
\hline 0.0012 & 0.987786 & 0.987308 & 0.986830 & 0.986352 \\
\hline 0.0014 & 0.987667 & 0.987189 & 0.986711 & 0.986233 \\
\hline 0.0016 & 0.987548 & 0.987070 & 0.986592 & 0.986115 \\
\hline \multicolumn{5}{|l|}{$c=0.9$} \\
\hline 0.0010 & 0.990249 & 0.990008 & 0.989767 & 0.989527 \\
\hline 0.0012 & 0.990189 & 0.989948 & 0.989707 & 0.989467 \\
\hline 0.0014 & 0.990129 & 0.989888 & 0.989648 & 0.989407 \\
\hline 0.0016 & 0.990069 & 0.989828 & 0.989588 & 0.989348 \\
\hline$c=1$. & & & & \\
\hline
\end{tabular}


Table 3: Fuzzy Availability corresponding to failure and repair rates of Separator

\begin{tabular}{|c|c|c|c|c|}
\hline \multirow[t]{2}{*}{$\downarrow \beta_{1}$} & P & \multicolumn{2}{|l|}{$\alpha_{1} \rightarrow$} & \multirow[b]{2}{*}{0.009} \\
\hline & 0.006 & 0.007 & 0.008 & \\
\hline \multicolumn{5}{|l|}{$c=0.0$} \\
\hline 0.41 & 0.968822 & 0.966538 & 0.964265 & 0.962002 \\
\hline 0.43 & 0.969461 & 0.967281 & 0.965110 & 0.962948 \\
\hline 0.45 & 0.970045 & 0.967958 & 0.965880 & 0.963812 \\
\hline 0.47 & 0.970579 & 0.968579 & 0.966587 & 0.964603 \\
\hline \multicolumn{5}{|l|}{$c=0.1$} \\
\hline 0.41 & 0.971040 & 0.968973 & 0.966915 & 0.964865 \\
\hline 0.43 & 0.971619 & 0.969645 & 0.967680 & 0.965722 \\
\hline 0.45 & 0.972146 & 0.970258 & 0.968377 & 0.966504 \\
\hline 0.47 & 0.972629 & 0.970820 & 0.969017 & 0.967221 \\
\hline \multicolumn{5}{|l|}{$c=0.2$} \\
\hline 0.41 & 0.973277 & 0.971429 & 0.969589 & 0.967755 \\
\hline 0.43 & 0.973794 & 0.972030 & 0.970273 & 0.968521 \\
\hline 0.45 & 0.974266 & 0.972578 & 0.970897 & 0.969221 \\
\hline 0.47 & 0.974697 & 0.973080 & 0.971469 & 0.969862 \\
\hline \multicolumn{5}{|l|}{$c=0.3$} \\
\hline 0.41 & 0.975534 & 0.973908 & 0.972287 & 0.970672 \\
\hline 0.43 & 0.975988 & 0.974436 & 0.972889 & 0.971347 \\
\hline 0.45 & 0.976403 & 0.974919 & 0.973439 & 0.971963 \\
\hline \multirow[t]{2}{*}{0.47} & 0.976783 & 0.975360 & 0.973942 & 0.972528 \\
\hline & 0.006000 & 0.007000 & 0.008000 & 0.009000 \\
\hline \multicolumn{5}{|l|}{$c=0.4$} \\
\hline 0.41 & 0.977810 & 0.976408 & 0.975010 & 0.973616 \\
\hline 0.43 & 0.978202 & 0.976864 & 0.975530 & 0.974199 \\
\hline 0.45 & 0.978559 & 0.977280 & 0.976004 & 0.974731 \\
\hline 0.47 & 0.978886 & 0.977660 & 0.976438 & 0.975218 \\
\hline \multicolumn{5}{|l|}{$c=0.5$} \\
\hline 0.41 & 0.980105 & 0.978930 & 0.977758 & 0.976589 \\
\hline 0.43 & 0.980434 & 0.979312 & 0.978194 & 0.977078 \\
\hline 0.45 & 0.980733 & 0.979661 & 0.978591 & 0.977524 \\
\hline 0.47 & 0.981007 & 0.979980 & 0.978955 & 0.977933 \\
\hline \multicolumn{5}{|l|}{$c=0.6$} \\
\hline 0.41 & 0.982421 & 0.981475 & 0.980532 & 0.979590 \\
\hline 0.43 & 0.982685 & 0.981783 & 0.980883 & 0.979984 \\
\hline 0.45 & 0.982925 & 0.982063 & 0.981202 & 0.980343 \\
\hline 0.47 & 0.983146 & 0.982320 & 0.981495 & 0.980672 \\
\hline \multicolumn{5}{|l|}{$c=0.7$} \\
\hline 0.41 & 0.984756 & 0.984043 & 0.983331 & 0.982620 \\
\hline 0.43 & 0.984955 & 0.984275 & 0.983596 & 0.982917 \\
\hline 0.45 & 0.985137 & 0.984486 & 0.983837 & 0.983188 \\
\hline 0.47 & 0.985303 & 0.984680 & 0.984058 & 0.983437 \\
\hline \multicolumn{5}{|l|}{$c=0.8$} \\
\hline 0.41 & 0.987111 & 0.985633 & 0.986156 & 0.985678 \\
\hline 0.43 & 0.987245 & 0.986789 & 0.986333 & 0.985878 \\
\hline 0.45 & 0.987367 & 0.986495 & 0.986495 & 0.986060 \\
\hline 0.47 & 0.987478 & 0.986643 & 0.986643 & 0.986227 \\
\hline \multicolumn{5}{|l|}{$c=0.9$} \\
\hline 0.41 & 0.989487 & 0.989247 & 0.989007 & 0.988766 \\
\hline 0.43 & 0.989555 & 0.989325 & 0.989096 & 0.988867 \\
\hline 0.45 & 0.989616 & 0.989397 & 0.989177 & 0.988958 \\
\hline 0.47 & 0.989672 & 0.989462 & 0.989252 & 0.989042 \\
\hline \multicolumn{5}{|l|}{$c=1.0$} \\
\hline $\begin{array}{l}\text { The val } \\
\beta_{1} \text { is } 0.9\end{array}$ & $\begin{array}{l}\text { fuzzy av } \\
4\end{array}$ & corre & to all & les of $\alpha$ \\
\hline
\end{tabular}

Now we see the effect of system coverage factor on the fuzzy availability with the failure rates of the subsystem separator and continuous butter making.

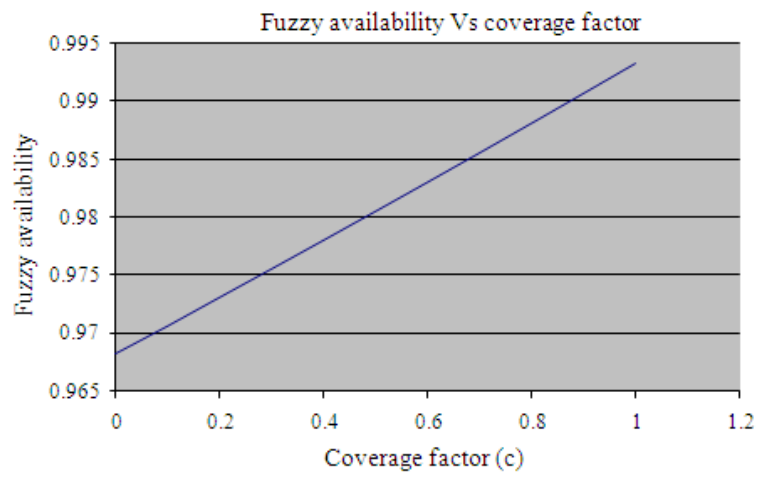

Fig. 2: Graph of coverage factor and fuzzy availability for separator and CBM

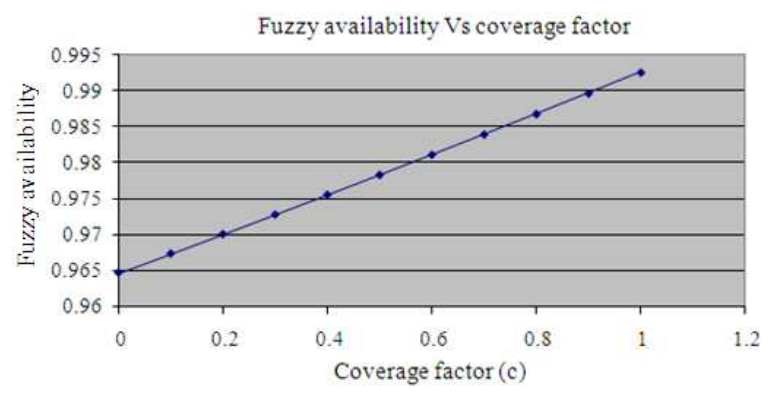

Fig. 3: Graph of coverage factor and fuzzy availability for separator and melting vats

Let the values be $\alpha_{1}=0.007, \alpha_{2}=0.0027$, $\alpha_{3}=0.0054, \quad \alpha_{4}=0.0009, \alpha_{5}=0.0027, \alpha_{6}=0.0055$, $\beta_{1}=0.41, \beta_{2}=0.40, \quad \beta_{3}=0.67, \beta_{4}=0.33, \beta_{5}=0.67$, $\beta_{6}=6.00$.

This is shown in Fig. 2.

Effect of failure rates of separator and melting vats on long run fuzzy availability: The effect on the system is studied by varying the values of $\alpha_{1}$ and $\alpha_{4}$. Let the values be $\alpha_{2}=0.0030, \alpha_{3}=0.0057, \alpha_{5}=0.0027$, $\alpha_{6}=0.0055, \beta_{1}=0.41, \beta_{2}=0.40, \beta_{3}=0.67, \beta_{4}=0.33$, $\beta_{5}=0.67, \beta_{6}=6.00$.

Now we will see the effect of system coverage factor on the fuzzy availability. For this let the values of failure and repair rates are: $\alpha_{1}=0.008, \alpha_{2}=0.0030$, $\alpha_{3}=0.0057, \alpha_{4}=0.0012, \alpha_{5}=0.0027, \alpha_{6}=0.0055$, $\beta_{1}=0.41, \quad \beta_{2}=0.40, \beta_{3}=0.67, \beta_{4}=0.33, \beta_{5}=0.67$, $\beta_{6}=6.00$

This effect is shown in Fig. 3.

Effect of failure and repair rate of separator on long run fuzzy availability: The effect on the system is studied by varying the values of $\alpha_{1}$ and $\beta_{1}$. Let the values be $\alpha_{2}=0.0033, \alpha_{3}=0.0056, \alpha_{4}=0.0014$, $\alpha_{5}=0.0027, \quad \alpha_{6}=0.0055, \quad \beta_{2}=0.40, \quad \beta_{3}=0.67$, $\beta_{4}=0.33, \beta_{5}=0.67, \beta_{6}=6.00$. 


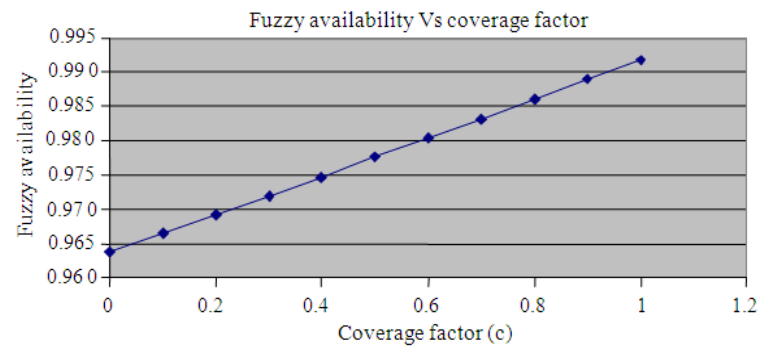

Fig. 4: Graph of Coverage Factor and fuzzy availability for separator with different failure and repair rates

Now we will see the effect of system coverage factor on the fuzzy availability. For this let the values of failure and repair rates are: $\alpha_{1}=0.009, \alpha_{2}=0.0033$, $\alpha_{3}=0.0056, \quad \alpha_{4}=0.0014, \quad \alpha_{5}=0.0027, \alpha_{6}=0.0055$, $\beta_{1}=0.45, \beta_{2}=0.40, \beta_{3}=0.67, \beta_{4}=0.33, \beta_{5}=0.67$, $\beta_{6}=6.00$.

This effect is shown in Fig. 4.

\section{DISCUSSION}

From Table 1, we see that as the failure rate of continuous butter making machine increases the fuzzy availability of the system decreases slowly and if we increase the failure rate of the separator the fuzzy availability decreases rapidly corresponding as the system coverage factor increases. From the plot in Fig. 2 it is clear that as the coverage factor increases, fuzzy availability increases. From Table 2, we see that as the failure rate of the sub-system melting vats increases, the fuzzy availability of the system decreases slowly but as we increases the failure rate of the subsystem separator increases, the fuzzy availability of the system decreases rapidly. From the plot in Fig. 3, it is clear that as the coverage factor increases, fuzzy availability increases. Table 3 shows that increase in failure rate of separator decreases the fuzzy availability of the system rapidly and increase in the repair rate of separator increases the fuzzy availability of the system. From the plot in Fig. 4, it is clear that as the coverage factor increases, fuzzy availability increases.

\section{CONCLUSION}

Analysis of fuzzy availability of butter-oil processing plant can help in increasing the production of the butter-oil. A comparative study of Table 1-3 and Fig. 1-4 reveals that sub-system A, i.e., separator has maximum effect on the long run fuzzy availability of the complete system. The effect of system coverage factor corresponding to values of failure and repair rate of sub-system a on long run fuzzy availability of system has also been presented graphically in Fig. 4. Other sub-systems are almost equally effective. Numeric results show that all the fuzziness, system coverage factor and maintenance have significant effects on the fuzzy availability of butter-oil processing plant.

Hence, it is recommended that management should pay more attention to sub-system A so that the overall performance of the system may improve.

\section{ACKNOWLEDGEMENT}

The researchers are grateful to the reviewers for their critical evaluation and suggested revisions for further improvement of the research.

\section{REFERENCES}

1. Cai, K.Y., 1996. Introduction to Fuzzy Reliability. Kluwer Academic Publishers, Norwell, MA., USA., ISBN: 0792397371, pp: 336.

2. Cai, K.Y., C.Y. Wen and M.L. Zhang, 1991. Fuzzy reliability modeling of gracefully degradable computing systems. Reliabil. Eng. Syst. Safe., 33: 141-157.

3. Chowdhury, S.G. and K.B. Misra, 1992. Evaluation of fuzzy reliability of a Non-series parallel network. Microelect. Reliabil., 32: 1-4. http://cat.inist.fr/?aModele $=$ afficheN\&cpsidt $=5111241$

4. Zuang, H.Z., 1995. Reliability analysis method in the presence of fuzziness attached to operating time. Microelect. Reliabil., 35: 1483-1487. DOI: 10.1016/0026-2714(94)00173-L

5. Cai, K.Y. and C.Y. Wen, 1990. Street-Lighting lamps replacement: A fuzzy viewpoint. Fuzzy Sets Syst., 37: 161-172. DOI: 10.1016/0165-0114(90)90039-9

6. Pandey, D. and S.K. Tyagi, 2007. Profust reliability of a gracefully degradable system. Fuzzy Sets Syst., 158: 794-803. DOI: 10.1016/j.fss.2006.10.022

7. Zadeh, L.A., 1968. Probability measures of fuzzy events. J. Math. Anal. Appl., 23: 421-427. http://wwwbisc.cs.berkeley.edu/zadeh/papers/Probability $\% 20$ measures\%20of\%20fuzzy\%20events\%201968.pdf

8. Verma, A.K. et al., 2007. Fuzzy-Reliability Engineering: Concepts and Applications. 1st Edn., Narosa Publishing House, UK., ISBN: 9788173196690 . pp: 289.

9. Cai, K.Y., C.Y. Wen and M.L. Zhang, 1991. Survivability index for CCNs: A measure of fuzzy reliability. Reliabil. Eng. Syst. Safe., 33: 71-99. http://cat.inist.fr/?aModele=afficheN\&cpsidt=19615595

10. Cai, K.Y., C.Y. Wen and M.L. Zhang, 1991. Fuzzy variables as a basis for a theory of fuzzy reliability in the possibility context. Fuzzy Sets Syst., 42: 145-172. DOI: 10.1016/0165-0114(91)90143-E

11. Cai, K.Y., C.Y. Wen and M.L. Zhang, 1993. Fuzzy states as a basis for a theory of fuzzy reliability. Microelect. Reliabil., 33: 2253-2263. http://cat.inist.fr/?aModele $=$ afficheN\&cpsidt $=3846987$ 